\title{
Thermal conversion of waste plastics into fuel oil
}

\begin{abstract}
As a means of converting abundant waste to wealth, thermal conversion of waste plastics of four different types (low and high density polyethylene (LDPE and HDPE), polypropylene ( $\mathrm{PP}$ ) and mixed plastics) was carried out in a batch reactor made of stainless steel at temperatures between 170 and $3000^{\circ} \mathrm{C}$ under atmospheric pressure. The vapor produced from melting the plastics was condensed to form the liquid hydrocarbon (fuel oil) product. Standards were followed for each of the waste plastics during the production process of the liquid fuel oil. The effect of reaction time and product yield were investigated. The physical properties measured include product density and specific gravity. The liquid products formed were characterized using FTIR spectrometer (Spectrum 100 Perkin-Elmer). The heat combustion properties of the fuels produced were compared using ASTM D240. Also the API gravity and Sulphur content analysis were carried out using the ASTM D4052 and 4053 respectively. The chemical properties of the liquid product were compared for each of the samples and it was found that they vary from each waste plastic. Each of the liquid products contained low sulfur, but each of them varied from each other.
\end{abstract}

Keywords: waste-plastic, liquid-fuel-oil, LDPE, HDPE, PP, mixed plastics, thermalconversion
Volume 2 Issue 8 - 2017

\author{
AS Olufemi,' SA Olagboye ${ }^{2}$ \\ 'Department of Chemical/Petroleum Engineering, Niger Delta \\ University, Wilberforce Island, Nigeria \\ ${ }^{2}$ Department of Chemistry, Ekiti State University, Nigeria
}

Correspondence: AS Olufemi, Department of Chemical/ Petroleum Engineering, Niger Delta University,Wilberforce Island, Nigeria, Email adestanford.olufemi@gmail.com

Received: July 31, 2017 | Published: November 16, 2017
Abbreviations: LDPE, low density polyethylene; HDPE, high density polyethylene; PP, polypropylene; PE, polyethylene; PS, polystyrene; PLF, pyrolysis liquid fuel

\section{Introduction}

In the last few decades, there has been a dramatic increase in industrial and urban activities, culminating in the need for people to adopt improved living conditions. This has led to an increase in the use of packaging materials, mainly in the form of plastic. Plastics have become an indispensable part of today's world. Due to their lightweight, durability, energy efficiency, coupled with ease of production and design flexibility. These polymers are employed in entire gamut of industrial and domestic areas. Plastics are produced from petroleum derivatives and are composed primarily of hydrocarbons, but also contain additives such as antioxidants, colorants and other stabilizers. ${ }^{1}$ Today about 129 million tons of plastics are produced annually all over the world, out of which 77 million tons produced from petroleum. ${ }^{1}$ Plastics are non-biodegradable polymers, mostly containing carbon, hydrogen, and a few other elements like nitrogen, chlorine. However, some plastics can also be made from renewable materials such as polylactic acid, obtainable from cellulosic materials. Plastic products are ubiquitous in modern society because they represent a convenient means to transport purchased goods from the markets, factories, supermarket to the home. Plastic products are plentiful, inexpensive to produce, sturdy yet low weight, and easy to store and transport. ${ }^{2}$ Due to its less-biodegradable nature, plastic wastes contribute significantly to the problem of waste management. Disposal of plastic wastes pose a great hazard to the environment and effective method has not been implemented. ${ }^{3}$

Nowadays, the production and usage of plastics have increased the percentage of municipal waste more than ever because of modern lifestyle and an urgent need for comfort. Consequently, the menace of ineffective and poor disposal of plastic waste has created serious social and environmental challenges. ${ }^{4}$ Of the total amount of municipal solid waste, a small percentage of these wastes are recyclable while the largest percentage is waste plastic. Most plastic wastes are separated into polyethylene (PE) and polypropylene (PP). ${ }^{3}$ Plastic waste is a big issue in most developing countries, because the amount of recycled plastic remains low due to the high investment needs and operating cost. ${ }^{5,6}$

However, the possibilities exist for the plastics to be recycled, treated and used as raw material, thereby reducing the large volume of waste and the extent of environmental nuisance the waste constitute to urban streets. Recycling of plastics already occurs on a wide scale. The most attractive technique of chemical feedstock recycling is pyrolysis. Thermal cracking or thermal pyrolysis involves the degradation of the polymeric materials by heating in the absence of oxygen. ${ }^{7}$ Pyrolysis is the thermo chemical decomposition of organic material at high temperatures. This process is a part of de-polymerization, which is in contrast to the creation of plastics which uses polymerization from syngas and crude oil. The liquid product obtained is attractive because its properties has shown its potential for use as a chemical feedstock or fuel. ${ }^{8}$ Recycling via pyrolysis is one of the promising methods for recycling waste plastics and involves thermo chemical decomposition of organic and synthetic materials at elevated temperatures in the absence of oxygen to produce fuels. The process is usually conducted at higher temperatures between $500-800^{\circ} \mathrm{C}$. These pyrolytic products can be divided into a liquid component, a gaseous component and solid residues. ${ }^{9}$ Scheirs et al. ${ }^{4}$ compared the waste plastic oil with petroleum products and they found that it can also be used as fuel in compression ignition engines.

Thermal cracking of polyethylene and polypropylene carried out at high temperatures produce an olefin mixture $\left(\mathrm{C}_{1}-\mathrm{C}_{4}\right)$ and aromatic compounds, including benzene, toluene and xylene while those carried out at lower temperatures $\left(400-500^{\circ} \mathrm{C}\right)$ produce three products: a high-calorific value gas, condensable hydrocarbon oil, and waxes..$^{10,11}$ A wax product, consisting of paraffin together with a carbonized char is obtained in the reactor during cracking at lower temperatures. The gaseous fraction can be used for the supply of the energy required for the pyrolysis after burning. The liquid element mainly consists 
of linear olefins and paraffin with $\mathrm{C}_{11}-\mathrm{C}_{14}$ carbon atoms with only traces of aromatic compounds. ${ }^{11}$ Different researchers have studied the effect of temperature and the type of reactor on the pyrolysis of waste plastics. ${ }^{1,3,5,7,11-13}$ Pyrolysis and catalytic reforming of municipal plastic waste, which comprise of polyethylene (PE), polypropylene (PP) and polystyrene (PS), as impurities, are also significant. These impurities were acidic and toxic and led to the easy deactivation of the catalyst in the case of the conversion of municipal plastic waste, which have been compared with the thermal degradation products from municipal plastic waste and model mixed plastics. ${ }^{13}$ After the process of pyrolysis, wax and carbon black were created. Liquid fuel created from pyrolysis has similar properties to the generic diesel oil and benzene oil. In the present investigation, the recycling of waste products based on PP, LDPE, HDPE, and mixed plastic was examined using pyrolytic method. This study identifies different fractions of liquid fuel from plastic wastes obtained by non-catalyst conventional slow pyrolysis.

\section{Materials and experimental setup}

\section{Materials}

The thermo chemical conversions of discarded plastic to crude plastic oil were conducted using a stainless steel pyrolysis batch reactor. The system contains a $30 \mathrm{~L}$ reactor, connected to a condenser unit via a pipe, which is obliquely projected from the centre of the cover of the reactor. Perkin Elmer FTIR (Fourier Transform Infrared Spectroscopy) Spectrum-100, employed for analytical purposes. FTIR program set up are elaborated, before sample run, visible light range were $400-4000 \mathrm{~cm}^{-1}$, taken scan number is 17 and resolution number is 4 .

\section{Experimental setup}

Discarded plastic wastes were collected and sorted by handpicking municipal waste dumps and street litters across Ado Ekiti, Ekiti State, Nigeria. The waste plastics were classified into polyethylene (PE), and polypropylene (PP), which have approximately $20 \%$ of dirty contaminated contents. The plastics were cleaned by soaking for about an hour in water, using detergent. They were thoroughly washed, sun dried for about five hours and shredded. The dried shredded plastic wastes were weighed (ranges from 400 grams to $3 \mathrm{~kg}$ ) and charged into the batch reactor without a catalyst. These plastic types were investigated individually. The reactor was covered using gaskets and sealed with the aid of, gasket seal to avoid leakage. The reactor was then placed on an LPG gas burner and was connected to the condenser and separating system.

A thermocouple was then placed in the reactor and heated gas burner while the temperature was maintained between $170-300^{\circ} \mathrm{C}$ starting at 170 to $300^{\circ} \mathrm{C}$ with an increments of 5 to $10^{\circ} \mathrm{C}$ in order to make the plastics change gradually. In a typical run, the reactor is heated without oxygen. The gaseous products were cooled in the condenser maintained at $5-15^{\circ} \mathrm{C}$. The cooled liquid from the process was called pyrolysis liquid fuel (PLF). The pyrolysis process involves the breakdown of large molecules into smaller molecules. Produced hydrocarbon with a small molecular mass can be separated by fractional distillation and then used as fuel and chemicals. The condensed products were measured and the yield of liquid products was determined by dividing the collected material by the weight of feeding plastics. The schematic diagram of the pyrolysis plant used to the produce pyrolysis liquid fuel (PLF) is shown in Figure 1.

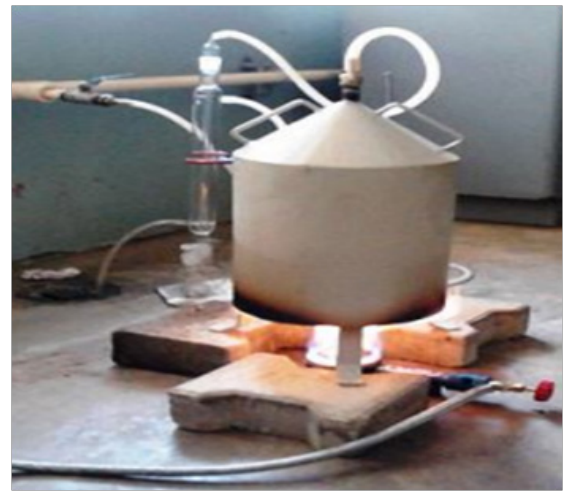

Figure I Pictorial and schematic diagrams of pyrolysis plant.

\section{Results and discussion}

The study of the production of liquid fuel oil from different plastic wastes in a pyrolysis laboratory plant at temperatures between 170$300^{\circ} \mathrm{C}$ has been conducted. Each experiment run time temperature was monitored properly to prevent overheating of the reactor. In the initial state of the experiments, the temperature profile rose from $170-222^{\circ} \mathrm{C}$ to melt the solid plastics. When the initial waste plastic sample melted, the first vapor production took an extra 30 minutes in each experiment. It was found that optimum and expected production captured is between $230-280^{\circ} \mathrm{C}$. The maximum production temperature to give optimum yield margin rose to $300^{\circ} \mathrm{C}$.

Once a sample finishes, the experiment shuts-down and was allowed to cool for 15 minutes. Subsequently the fuel oils produced were allowed to cool; the characterization was done using FT-IR

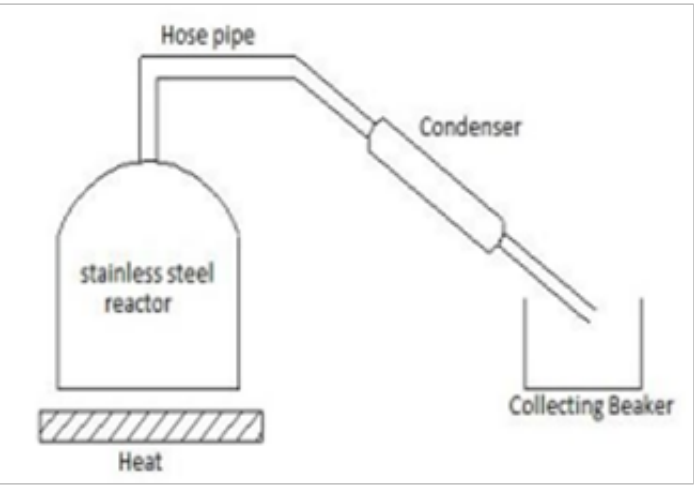

spectrometer (Spectrum 100 Perkin-Elmer). The heat combustion properties of the fuels produced were compared using ASTM D240. Also the API gravity and Sulphur content analysis were carried out using the ASTM D4052 and 4053 respectively. Figure 2 presents some product samples from the pyrolysis process.

\section{Physical analysis of products}

The preliminary tests on the produced liquid fuel have shown that it is a mixture of various hydrocarbons having a range of carbon chain lengths for HDPE plastics to fuel $\mathrm{C}_{3}$ to $\mathrm{C}_{28}$, LDPE plastics to fuel from $\mathrm{C}_{3}$ to $\mathrm{C}_{28}$ PP plastics to fuel $\mathrm{C}_{3}$ to $\mathrm{C}_{25}$ and mixed plastics to fuel from $\mathrm{C}_{6}$ to $\mathrm{C}_{18}$. The produced fuel density individually elaborated such as HDPE fuel density is $0.782 \mathrm{~g} / \mathrm{ml}$, LDPE fuel density is $0.771 \mathrm{~g} /$ $\mathrm{ml}$, PP fuel density is 0.759 and mixed plastic fuel density is 0.916 (Table 1). In equivalent to obtaining the liquid hydrocarbon fuel we 
also received light gaseous hydrocarbon compounds $\left(\mathrm{C}_{1}-\mathrm{C}_{4}\right)$ which resembles natural gas and table is showing individual plastic to fuel production yield \%, light gas \% and solid residue \% (Table 2). Every individual waste plastic to fuel production experiment takes time of
5-6 hours and also input electricity for every individual experiment 14-15 kWh for 1 gallon production. Light gas wash by alkali wash and light gas analysis under consideration.
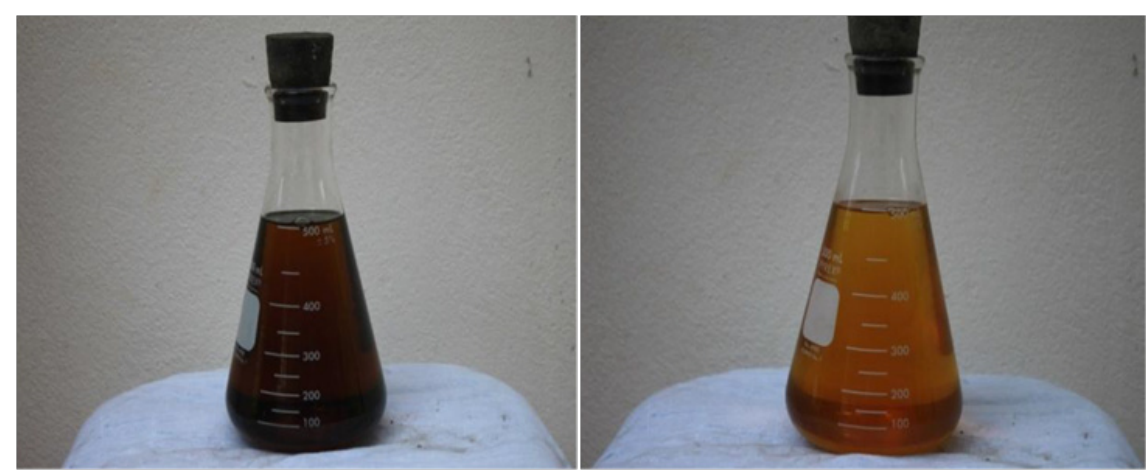

Figure 2 Some samples of the products.

Table I Individual Waste Plastic to Fuel Production Yield Percentage

\begin{tabular}{lllll}
\hline $\begin{array}{llll}\text { Name of waste } \\
\text { plastic fuel }\end{array}$ & $\begin{array}{l}\text { Fuel density } \\
\mathbf{g} / \mathbf{m l}\end{array}$ & Specific gravity & Fuel color & Fuel appearance \\
\hline PP & 0.759 & 0.7582 & Light brown, light transparent & Wax and ash contain present \\
LDPE & 0.771 & 0.772 & Yellow, no transparent & Cloudy, wax and ash contain present \\
HDPE & 0.782 & 0.7812 & Yellow, light transparent & Wax and ash contain present \\
Mixed Plastic & 0.916 & 0.915 & Light yellow, no transparent & Cloudy, wax and ash contain present \\
\hline
\end{tabular}

Table 2 Individual Waste Plastic to Fuel Production Yield Percentage

\begin{tabular}{llll}
\hline Name of waste plastic & Fuel production yield \% & Light gas $\left(\mathbf{C}_{\mathbf{1}}-\mathbf{C}_{\mathbf{4}}\right) \%$ & Solid residue \% \\
\hline PP & 91.981 & 2.073 & 5.944 \\
LDPE & 87.972 & 5.806 & 6.221 \\
HDPE & 89.354 & 5.345 & 5.299 \\
Mixed Plastic & 85.331 & 6.995 & 7.674 \\
\hline
\end{tabular}

\section{Effect of reaction temperature}

The pyrolysis process temperatures of liquid fuel oils from municipal waste plastics (PP, LDPE, HDPE and mixed plastic) are shown in Figure 3. It can be seen that the reaction temperatures of the plastic vary almost up to $300^{\circ} \mathrm{C}$, and that these are the temperatures that the plastic types change from a solid state to liquid and vapor. The plastic types have different temperature ranges. PP has an average reaction temperature of $225^{\circ} \mathrm{C}$. LDPE has an average reaction temperature of $210^{\circ} \mathrm{C}$. HDPE has an average reaction temperature of $213^{\circ} \mathrm{C}$. And mixed plastic has an average reaction temperature of $197^{\circ} \mathrm{C}$. The plastic types used different timeframes for their reaction, which is equally significant. PP and LDPE took 210 and 230 minutes to react respectively. While HDPE took 220 minutes to react. And the mixed plastic reaction time was 260 minutes. The differing temperatures that resulted in decomposition reactions provided hydrocarbons of different chain lengths. Pyrolysis of waste plastic grocery bags at temperatures of $420-440^{\circ} \mathrm{C}$ obtained a $74 \%$ yield of liquid product, referred to as plastic crude oil. ${ }^{2}$ This study shows, when the temperature increases the yield of liquid products having low boiling points and gas products increases. The reason for this is during the oxidation degradation process, oxygen from air bonded to the organic compounds and this caused the formation of peroxides first. In this reaction series, the oxygen committed to the organic compounds at the end of the reactions produced the high liquid yield. ${ }^{12}$

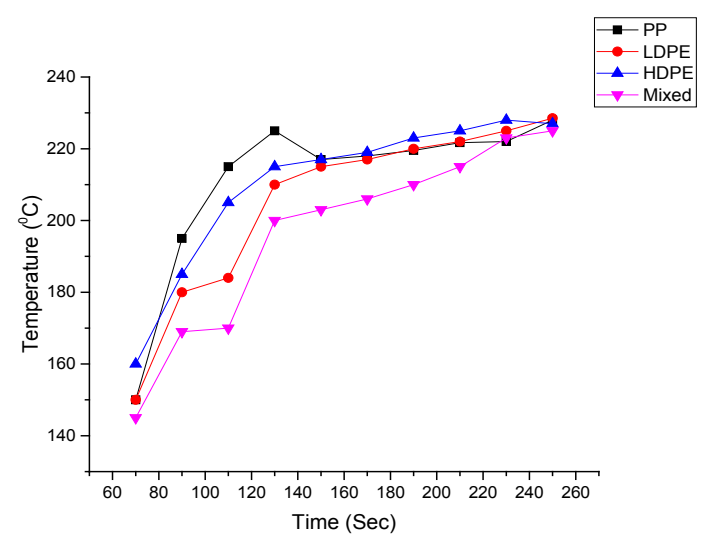

Figure 3 Influence of reaction temperature on the yield of liquid fuel. 


\section{ASTM test results}

Tables $3 \& 4$ show some ASTM test results of the individual waste plastic to fuel. The waste plastic fuel oil fuel properties were carried out at PAX ${ }^{\circledR}$ Laboratory Limited, Port Harcourt, Rivers State, Nigeria. The results of the tests are presented, as shown in Tables $3 \& 4$.

Table 3 Waste plastic individual fuel Btu and Mega Joule/gallon value

\begin{tabular}{llll}
\hline Name of waste plastic to fuel & ASTM test method & Gross heat of combustion Btu/Gal & Mega Joule/Gal \\
\hline HDPE & D240 & 123,845 & 130.66 \\
LDPE & D240 & 126,247 & 133.19 \\
PP & D240 & 125,307 & 132.2 \\
Mixed Plastic & D240 & 134,202 & 141.59 \\
\hline
\end{tabular}

Table 4 Individual Fuels API Gravity and Sulphur Content

\begin{tabular}{llllll}
\hline Name of waste plastic to fuel & ASTM test method & HDPE & LDPE & PP & Mixed plastic \\
\hline D4052 & API Gravity & 53.7 & 53 & 56.4 & 25.1 \\
& @ 60 OF & OAPI & OAPI & OAPI & OAPI \\
\hline D4053 & Sulphur & $3.05 \mathrm{pPm}$ & $2.10 \mathrm{pmm}$ & $<1.0 \mathrm{pPm}$ & $4.50 \mathrm{pPm}$ \\
\hline
\end{tabular}

FT-IR (fourier transform infra-red spectroscopy) analysis

According to spectrum band peak different number of wave number emerged and in versus of peak wave number several kinds of functional radicals are obtained from the FT-IR (Fourier Transform Infra-red Spectroscopy). Notice that in some near about wave numbers is sited between in the range and same compounds are derived.

HDPE sp/Spectrum.lst Euclidean Search Hit List: 0.969 K00939 L21468.DX 1-NONADECENE, 0.967 K00878 L14224.DX 1-HEXADECENE, 0.959 K01293 L66086.DX 1-OCTADECENE, 0.959 K01078 L66086.DX 1-OCTADECENE, 0.955 K00886 L14513. DX 1-ICOSENE, 0.953 K00913 L17800.DX 1-HEPTADECENE, 0.952 DA1102 OCTADECENE-1 (LIQUID FILM), 0.951 K00989 L26271.DX 1-PENTADECENE, 0.945 DA1101 HEXADECENE-1 (LIQUID FILM), 0.945 DA1100 TETRADECENE-1 (LIQUID FILM) (Fluka library transferred from 7000) (Table 5).

Table 5 For HDPE Fuel

\begin{tabular}{lll}
\hline Band serial & Wave number $\left(\mathbf{c m}^{-1}\right)$ & Functional group name \\
\hline 2 & 2956.38 & $\mathrm{C}^{-} \mathrm{CH}_{3}$ \\
3 & 2853.19 & $\mathrm{CH}_{2}$ \\
4 & 1641.69 & Non-Conjugated \\
7 & 1465.41 & $\mathrm{CH}_{3}$ \\
8 & 991.76 & $-\mathrm{CH}=\mathrm{CH}_{2}$ \\
9 & 965.02 & $-\mathrm{CH}=\mathrm{CH}-($ Trans $)$ \\
12 & 909.08 & $-\mathrm{CH}=\mathrm{CH}$ \\
14 & 721.39 & $-\mathrm{CH}=\mathrm{CH}-($ cis $)$ \\
15 & 667.88 & $-\mathrm{CH}=\mathrm{CH}-($ cis $)$ \\
\hline
\end{tabular}

LDPE sp/Spectrum.lst Euclidean Search Hit List: 0.971 K00878 L14224.DX 1-HEXADECENE, 0.970 K00939 L21468.DX
1-NONADECENE, 0.963 K01293 L66086.DX 1-OCTADECENE, 0.963 K01078 L66086.DX 1-OCTADECENE, 0.955 K00989 L26271. DX 1-PENTADECENE, 0.954 K00886 L14513.DX 1-ICOSENE, 0.953 K00825 L12200.DX 1-TRIDECENE, 0.951 K00913 L17800. DX 1-HEPTADECENE，0.951 F74740 1-OCTADECENE 0.947 DA1100 TETRADECENE-1 (LIQUID FILM) (Fluka library transferred from 7000) (Table 6).

Table 6 For LDPE Fuel

\begin{tabular}{lll}
\hline Band serial & Wave number $\left(\mathbf{c m}^{-1}\right)$ & Functional group name \\
\hline 2 & 2956.72 & $\mathrm{C}^{-} \mathrm{CH}_{3}$ \\
3 & 2922.13 & $\mathrm{C}^{-\mathrm{CH}_{3}}$ \\
4 & 2853.5 & $\mathrm{CH}_{2}$ \\
7 & 1641.78 & $\mathrm{Non}-$ Conjugated \\
8 & 1458.43 & $\mathrm{CH}_{3}$ \\
9 & 1377.96 & $\mathrm{CH}_{3}$ \\
12 & 964.96 & $-\mathrm{CH}=\mathrm{CH}-($ Trans $)$ \\
14 & 909.1 & $-\mathrm{CH}=\mathrm{CH}$ \\
15 & 887.93 & $\mathrm{CH}=\mathrm{CH}$ \\
16 & 721.71 & $-\mathrm{CH}=\mathrm{CH}$-(cis) \\
17 & 667.91 & $-\mathrm{CH}=\mathrm{CH}$-(cis) \\
\hline
\end{tabular}

PP .sp/Spectrum.lst Euclidean Search Hit List: 0.904 K00787 L10678.DX 2, 4-DIMETHYL-1-HEXENE, 0.898 K01163 L58486. DX 2， 6-DIMETHYL-1-HEPTENE， 0.895 K01158 L58451. DX 2, 4-DIMETHYL-1-HEPTENE, 0.881 K00811 L11245. DX 2， 4-DIMETHYL-1-PENTENE, 0.867 K00784 L10670. DX 2-METHYL-1-HEPTENE 0.857 K01166 L58489.DX 2, 5-DIMETHYL-1-HEXENE, 0.850 K00866 L13612.DX 2-METHYL1-HEXENE, 0.843 K00794 L10687.DX 2, 3-DIMETHYL-1HEXENE, 0.839 K01316 L67876.DX 2-METHYL-1-PENTENE, 
0.820 K00529 L02241.DX 2-ETHYL-1-HEXENE (Fluka library transferred from 7000) (Table 7).

Table 7 For PP Fuel

\begin{tabular}{lll}
\hline Band serial & Wave number $\left(\mathbf{c m}^{-1}\right)$ & Functional group name \\
\hline 2 & 3074.99 & $\mathrm{H}$ bonded $\mathrm{NH}$ \\
3 & 2955.87 & $\mathrm{C}^{-} \mathrm{CH}_{3}$ \\
4 & 2912.71 & $\mathrm{C}^{-\mathrm{CH}_{3}}$ \\
7 & 2871.87 & $\mathrm{C}^{-\mathrm{CH}_{3}}$ \\
8 & 1650.2 & $\mathrm{Amides}$ \\
9 & 1465.95 & $\mathrm{CH}$ \\
12 & 1377.07 & $\mathrm{CH}$ \\
14 & 965.06 & $-\mathrm{CH}=\mathrm{CH}-($ Trans $)$ \\
15 & 887.02 & $\mathrm{CH}=\mathrm{CH}$ \\
16 & 739.06 & $-\mathrm{CH}=\mathrm{CH}-(\mathrm{cis})$ \\
\hline
\end{tabular}

Mixed plastics.sp/Spectrum.lst Euclidean Search Hit List: 0.749 K00748 L10290.DX STYRENE, 0.749 K00811 L10290.DX STYRENE, 0.749 K00419 L10290.DX STYRENE, 0.742 PT0523 STYRENE (10-15PPM TERT-BUTYL CATECHOL) 0.742 PA0117 STYRENE, 0.671 F13280 BENZYL CHLORIDE, 0.663 K00462 L00638.DX 1, 1-DIPHENYLETHYLENE, 0.643 K01369 L74757. DX 4-METHYL-2,4-DIPHENYL-1-PENTENE $0.630 \quad$ K01318 L67879.DX CIS-STILBENE, 0.613 K00351 K59427.DX 1,2BIS(DIPHENYLMETHYLENE)CYCLOBUTANE (Fluka library transferred from 7000) (Table 8).

Table 8 For Mixed Plastic Fuel

\begin{tabular}{lll}
\hline $\begin{array}{l}\text { Band serial } \\
\text { number }\end{array}$ & Wave number $\left(\mathbf{c m}^{-1}\right)$ & Functional group name \\
\hline 2 & 3083.59 & $=\mathrm{C}-\mathrm{H}$ \\
3 & 3060.73 & $=\mathrm{C}-\mathrm{H}$ \\
4 & 2966.73 & $=\mathrm{C}-\mathrm{H}$ \\
7 & 2874.03 & $\mathrm{C}-\mathrm{CH}_{3}$ \\
8 & 1802.56 & $\mathrm{Non}-\mathrm{Conjugated}$ \\
9 & 1630.02 & $\mathrm{Conjugated}$ \\
12 & 1414.28 & $\mathrm{CH}_{2}$ \\
14 & 1376.1 & $\mathrm{CH}$ \\
15 & 1028.94 & $\mathrm{Acetates}$ \\
16 & 990.91 & $-\mathrm{CH}_{3} \mathrm{CH}$ \\
17 & 729.65 & $-\mathrm{CH}=\mathrm{CH}_{2}(\mathrm{cis})$ \\
\hline
\end{tabular}

The comparative study of HDPE, LDPE, PP and Mixed Plastics fuel oil emerging that in different bands and wave number different functional groups and compound derived. In some cases the wave number is matched with one wave to another wave number, including compound identification is also found same compound or group. In HDPE, LDPE, PP and Mixed Plastics fuel oil common functional groups are $\mathrm{CH}_{3}, \mathrm{C}-\mathrm{CH}_{3}, \mathrm{CH}_{2},-\mathrm{CH}=\mathrm{CH}$-(cis) and $-\mathrm{CH}=\mathrm{CH}$-(trans). The spectrum feature of each individual fuel is uniquely identified. Although the wave number and spectrum band very near to each other so that derived compound functional group mostly common in the radical group. Noticeable that wave number of each individual fuel ascending to $700 \mathrm{~cm}^{-1}$ to $750 \mathrm{~cm}^{-1}$ and most probably compound is $-\mathrm{CH}=\mathrm{CH}-(\mathrm{cis})$ and $-\mathrm{CH}=\mathrm{CH}$-(trans) groups. Besides common group available functional radical are also present in each fuel such as $\mathrm{C}-\mathrm{CH}_{3}, \mathrm{C}=\mathrm{CH}_{2},-\mathrm{CH}=\mathrm{CH}_{2},=\mathrm{C}-\mathrm{H}$ and so on.

\section{Conclusion}

The comparative study of densities found that the HDPE fuel density is $0.782 \mathrm{~g} / \mathrm{ml}$, LDPE fuel density is $0.771 \mathrm{~g} / \mathrm{ml}$, PP fuel density is $0.759 \mathrm{~g} / \mathrm{ml}$ and mixed plastic fuel density is $0.916 \mathrm{~g} / \mathrm{ml}$. Similarly, the FTIR analysis of each individual fuel oil found that most of the functional group and compound are not unique from each other, they vary for different types of compounds. The comparative study of their chemical structures shows that in HDPE and LDPE similar $-\mathrm{CH}_{2}-$ and $-\mathrm{CH}_{3}$ - group appear in their polymer chain. However, in PP and mixed plastics, both structures contain aromatic benzene compound including methylene group, but PP contain a methyl $\left(-\mathrm{CH}_{3}-\right)$ group that is not found in mixed plastics. Likewise, mixed plastics contain plenty of methylene, benzene monomer in the long chain hydrocarbon.

From the findings above, it can then be concluded that:

a. The thermal conversion is an effective way of reducing municipal waste plastics.

b. Thermal conversion of municipal waste plastics yields economic benefits.

c. No environmental hazard(s) since the products formed contain negligible sulphur content.

\section{Acknowledgements}

None.

\section{Conflict of interest}

The author declares no conflict of interest.

\section{References}

1. Santaweesuk C, Janyalertadun A. The Production of Fuel Oil by Conventional Slow Pyrolysis Using Plastic Waste from a Municipal Landfill. IJESD. 2017;8(3):168-173.

2. Sharma BK, Moser BR, Vermillion KE, et al. Production, characterization and fuel properties of alternative diesel fuel from pyrolysis of waste plastic grocery bags. Fuel Processing Technology. 2014;122:79-90.

3. Wami EN, Ugoha VIP. Liquid Fuels Derivative from Pyrolysis of Packaged Water Sachets (Low Density Polyethylene, LDPE). Journal of the Nigerian Society of Chemical Engineers. 2006;21:125-131.

4. Scheirs J, Kaminsky W. Feedstock recycling and pyrolysis of waste plastics: converting waste plastics into diesel and other fuels. USA: J Wiley \& Sons; 2006. 816 p.

5. Wami EN, Emesiobi FC, Ugoha VIP. Suitability of Recycled Waste Plastic Bags. As Aggregate for Highway Consruction: The Nigerian Experience. Nigerian Society of Chemical Engineers NSChE. 2004.

6. Njiribeako IA, Kathleen EG. Management of Non-Biodegradable Wastes in Nigeria. Journal of Engineering Management. 2003;4(2):9-12. 
7. Kumar S, Singh RK. Recovery of Hydrocarbon Liquid from Waste High Density Polyethylene by Thermal Pyrolysis. Braz J Chem Eng. 2011;28(4):659-667.

8. Sarker M, Rashid MM, Molla M, et al. Method of Converting Municipal Proportional Waste Plastics into Liquid Hydrocarbon Fuel by Using Activated Carbon. International Journal of Materials and Chemistry. 2012;2(5):208-217.

9. Aguado J, Miguel GS, Serrano DP, et al. Feedstock recycling of polyethylene in a two-step thermo-catalytic reaction system. Journal of Analytical and Applied Pyrolysis. 2007;79(1):415-423.

10. Achilias DS, Roupakias C, Megalokonomos $\mathrm{P}$, et al. Chemical recycling of plastic wastes made from polyethylene (LDPE and HDPE) and polypropylene (PP). J Hazard Mater. 2007;149(3):536-542.
11. Aguado J, DP Serrano. Feedstock recycling of plastic wastes. Royal society of chemistry. UK, 1999. 1:192 p.

12. Koca A, Bilgesub AY. Catalytic and thermal oxidative pyrolysis of LDPE in a continuous reactor system. Journal of Analytical and Applied Pyrolysis. 2007;78(1):7-13.

13. Wang JL, Wang LL. Catalytic pyrolysis of municipal plastic waste to fuel with nickel-loaded silica-alumina catalysts. Energy Sources, Part A: Recovery, Utilization, and Environmental Effects. 2011;33(21):19401948. 